\title{
Silver(I)-catalyzed $\mathbf{C}-\mathbf{X}, \mathbf{C}-\mathbf{C}, \mathbf{C}-\mathbf{N}$ and $\mathbf{C}-\mathbf{O}$ cross couplings us- ing aminoquinoline directing group via elusive aryl-Ag(III) species
}

\author{
Lorena Capdevila, ${ }^{1}$ Erik Andris, ${ }^{2}$ Anamarija Briš,${ }^{2,3}$ Màrius Tarrés, ${ }^{1}$ Steven Roldán-Gómez, ${ }^{1}$ Jana \\ Roithová, ${ }^{2,4 *}$ Xavi Ribas ${ }^{1 *}$
}

\author{
${ }^{1}$ Institut de Química Computacional i Catàlisi (IQCC) and Departament de Química, Universitat de Girona, Cam- \\ pus de Montilivi, E-17071 Girona, Catalonia, Spain \\ ${ }^{2}$ Department of Organic Chemistry, Faculty of Science, Charles University, Hlavova 2030/8, 12843 Prague 2, Czech \\ Republic. \\ ${ }^{3}$ Ruđer Bošković Institute, Bijenička 54, 10 ooo Zagreb, Croatia. \\ ${ }^{4}$ Institute for Molecules and Materials, Radboud University, Heyendaalseweg 135, 6525 AJ Nijmegen, Netherlands.
}

\begin{abstract}
Cross-coupling transformations are a powerful tool in organic synthesis. It is known that this kind of transformations undergoes 2-electron redox processes and, for this reason, silver has been nearly forgotten as catalyst for cross-couplings since silver is mainly considered as a 1-electron redox metal. Herein, we disclose effective $\mathrm{Ag}(\mathrm{I})$-catalyzed cross-coupling transformations using bidentate aminoquinoline as a directing group towards different nucleophiles to form C-C, C-N and C-O bonds. DFT calculations indicate the feasible oxidative addition of $\mathbf{L}_{\mathbf{1}} \mathbf{-} \mathbf{I}$ substrate via $\mathrm{Ag}(\mathrm{I}) / \mathrm{Ag}(\mathrm{III})$ catalytic cycle. Furthermore, ion spectroscopy experiments suggest a highly reactive aryl-Ag(III) that in absence of nucleophiles reacts to form an intermolecular cyclic product $\left[{ }_{5} \mathbf{d}-\mathbf{A g}(\mathbf{I})-\mathbf{C H}_{3} \mathbf{C N}\right]$, which in solution forms $5 \mathbf{a}$. This work proves that silver can undergo 2-electron redox processes in cross-coupling reactions like $\mathrm{Pd}$ and $\mathrm{Cu}$.
\end{abstract}

KEYWORDS. Silver, Cross-Coupling, Two-Electron Redox Catalysis, Mass Spectrometry, Infrared Photodissociation Spectroscopy.

\section{INTRODUCTION}

The vast majority of C-heteroatom cross-coupling processes are governed by palladium (C-N, BuchwaldHartwig) and copper (Ullmann-type) catalysis, constructing a myriad of scaffolds useful as pharmaceuticals, materials, etc. ${ }^{1-5}$ However, there is continuous need to discover new synthetic tools in order to have in hand versatile solutions for a given cross-coupling transformation. Silver has been completely forgotten in its use as catalyst for cross-coupling, ${ }^{6-7}$ which typically undergoes 2-electron redox processes, since it is generally believed that Ag only shows 1-electron redox chemistry. ${ }^{8-9}$ Nevertheless, albeit scarce, there are reports showing that silver catalyzes Sonogashira-type couplings ${ }^{10}$ and Ullmann-type $\mathrm{C}-\mathrm{N}$ and C-O couplings, ${ }^{11}$ although with complete lack of mechanistic understanding. In that respect, our group reported the unprecedented experimental evidence that 2-electron redox $\mathrm{Ag}(\mathrm{I}) / \mathrm{Ag}(\mathrm{III})$ catalysis can take place if the right coordination environment is provided to stabilize the key aryl-Ag(III) intermediate species (Scheme 1a,b,c). ${ }^{9}$ It was shown that triazamacrocylic aryl-Br substrates enforced an ideal square-planar environment to stabilize aryl$\mathrm{Ag}$ (III) species formed through facile oxidative addition at $\mathrm{Ag}(\mathrm{I})$. Strikingly, the aryl-Ag(III) species reacted with Oand $\mathrm{C}$-nucleophiles under mild conditions via 2-electron reductive elimination, and the whole cross-coupling process could be engaged in a catalytic mode.

In the present work, we aim at transferring the Agcatalyzed cross-coupling reactions into non-cyclic arylhalide substrates by using bidentate aminoquinoline (AQ) directing group, thus exploring the limits of the transient stabilization of the putative aryl-Ag(III) in a nonconstrained system. To that end, we used $\mathbf{L}_{\mathbf{1}}-\mathbf{I}$ as model substrate (see Figure 1) and investigated the silver catalysis for halide exchange reactions, Ullmann-type C-N and $\mathrm{C}-\mathrm{O}$ couplings, and Hurtley-type $\mathrm{C}-\mathrm{C}$ couplings with active methylene nucleophiles. ${ }^{12-14}$ The implication of putative aryl-Ag(III) species has been analyzed by helium and $\mathrm{D}_{2}$ tagging infrared photodissociation (IRPD) spectroscopy ${ }^{15-19}$ and will be discussed in detail. 
a)

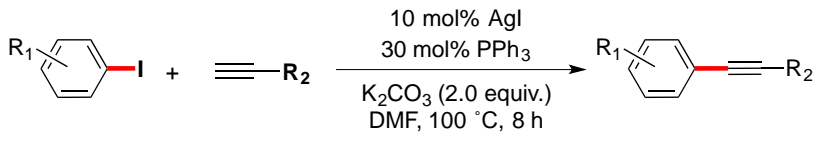

b)

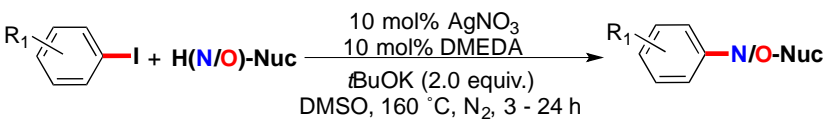

HN-Nuc : Heterocyclic Amines, Anilines, Benzamides HO-Nuc : Phenols, alkylic Alcohols

c)

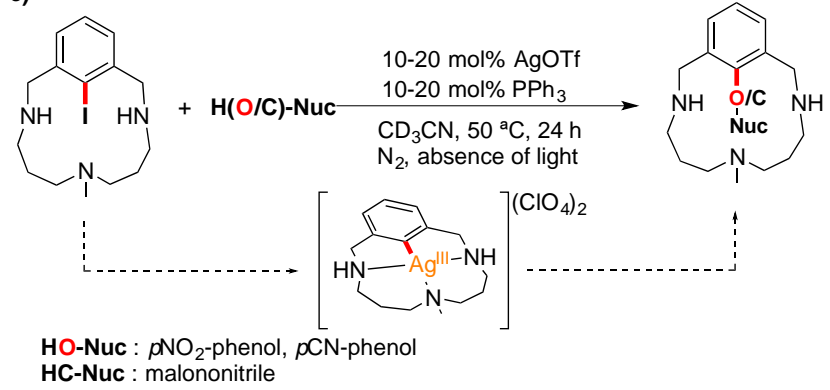

Scheme 1. a) Ag-catalyzed Sonogashira-type coupling. b) Ag-catalyzed Ullmann-type $\mathrm{C}-\mathrm{N}$ and $\mathrm{C}-\mathrm{O}$ reaction. c) Ag-catalyzed $\mathrm{C}-\mathrm{O}$ and $\mathrm{C}-\mathrm{C}$ bond forming crosscoupling reaction. ${ }^{9}$

\section{RESULTS AND DISCUSSION}

We had previously shown that well-defined aryl-Ag(III) could undergo reductive elimination with different halides to effectively afford the halide exchange reaction within aryl-halide triazamacrocycles. ${ }^{9}$ More importantly, the system was catalytic in $\operatorname{Ag}(\mathrm{I})$ for the aryl-iodide to aryl-Br exchange. In this work we started by analyzing the ability of $\mathrm{Ag}(\mathrm{I})$ to catalyze the halide exchange reactions using non-cyclic aryl-halide substrates bearing an aminoquinoline bidentate Directing Group (DG), ligands $\mathbf{L}_{\mathbf{1}} \mathbf{-} \mathbf{X}$, $\mathbf{L}_{\mathbf{2}}-\mathbf{X}$ (X = I, Br, Cl, F; Figure 1). This non-cyclic model substrate enforces a square-planar coordination upon oxidative addition at $\operatorname{Ag}(\mathrm{I})$, reduces from three to two the number of $\mathrm{N}$-coordination sites compared to the triazamacrocyclic substrates, and loses the macrocyclic effect.
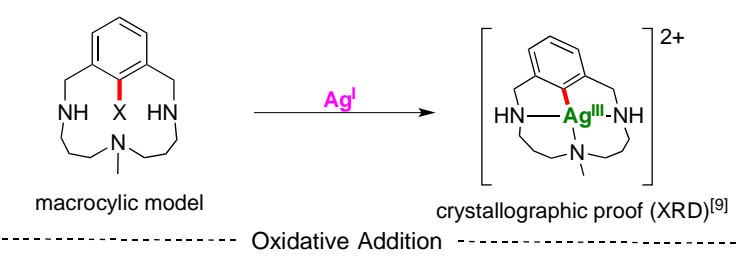

open model system

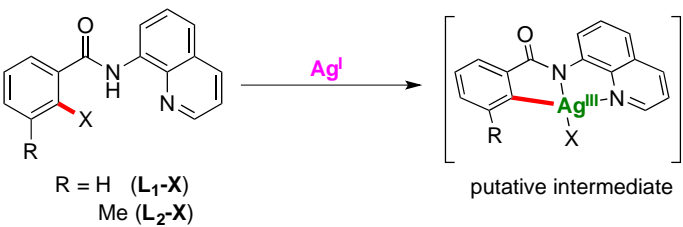

Figure 1. Macrocyclic model ${ }^{9}$ and open model system were compared in oxidative addition step.

Thus, we analyzed first the viability of this halide exchange catalysis using $\mathbf{L}_{\mathbf{1}}-\mathbf{I}$ with $\mathrm{nBu}_{4} \mathrm{NX}$ salts $(\mathrm{X}=\mathrm{Cl}, \mathrm{Br})$. After optimization, we found that the catalysis was effective at $100{ }^{\circ} \mathrm{C}$ for the coupling with $\mathrm{Cl}$ and $\mathrm{Br}$ using 10 mol \% of $\mathrm{Ag}(\mathrm{I}) \mathrm{OTf}$ (see Table 1). The catalysis can be performed in $\mathrm{CH}_{3} \mathrm{CN}$ or DMSO solvents, affording goodto-excellent yields. The high reaction temperatures needed to achieve the halide exchange suggested a significantly higher energy barrier for the oxidative addition step in $\mathbf{L}_{\mathbf{1}}$-I than in the triazamacrocyclic aryl-I model substrate, where the reaction was conducted at room temperature (in agreement with DFT study, see below). When $\mathbf{L}_{\mathbf{1}}-\mathbf{B r}$ was used as substrate with $\mathrm{nBu}_{4} \mathrm{NX}$ salts $(\mathrm{X}=\mathrm{Cl}, \mathrm{I})$, the $\mathrm{Br}$-to- $\mathrm{Cl}$ exchange was optimized in DMSO affording up to $78 \%$ yield. On the other hand, the $\mathrm{Br}$-to-I exchange could only be optimized to afford a $38 \%$ yield in $\mathrm{CH}_{3} \mathrm{CN}$ when $20 \mathrm{~mol} \%$ of AgOTf was used as catalyst. This could be increased up to $50 \%$ when $20 \mathrm{~mol} \%$ of $\mathrm{PPh}_{3}$ was used as an additive (we also observed the beneficial use of $\mathrm{PPh}_{3}$ as additive in cross-coupling catalysis using the triazamacrocyclic aryl-I substrate). ${ }^{9}$ When $\mathbf{L}_{\mathbf{1}}-\mathbf{C l}$ was used as substrate, no halide exchange reaction occurred and $\mathbf{L}_{\mathbf{1}}-$ Cl was fully recovered, presumably due to the unsurmountable energetic barrier for the oxidative addition under these conditions.

Given that the halide-exchange catalysis proved that the activation of aryl-I and aryl-Br was feasible via silvercatalysis, we aimed at exploring the ability of generating $\mathrm{C}-\mathrm{N}$ heteroatom bonds, using aliphatic amines as nucleophiles, as well as imidazole and anilines (Table 2). Under optimized conditions (DMSO as solvent and CsF as base), couplings with cyclohexanamine and cyclopentanamine afforded moderate yields of the coupling products (37$53 \%$ yield), as depicted in Table 2. Similarly, when imidazole was used, the coupling product $\mathbf{2 c}$ was obtained in $59 \%$ yield. We then tested para-substituted anilines $\left(\mathrm{NO}_{2}-\right.$ or MeO-), and they afforded a $79 \%$ yield of $\mathbf{2} \mathbf{d}\left(\mathrm{NO}_{2}\right)$ and a moderate $33 \%$ yield of $2 \mathrm{f}$ (OMe). The beneficial electron-withdrawing effect of the $\mathrm{NO}_{2}$ group suggested that the underlying mechanism for $\mathrm{C}-\mathrm{N}$ couplings might be related to a facile deprotonation of the $\mathrm{N}$-nucleophile. 
Table 1. Ag-catalyzed halide exchange reactions

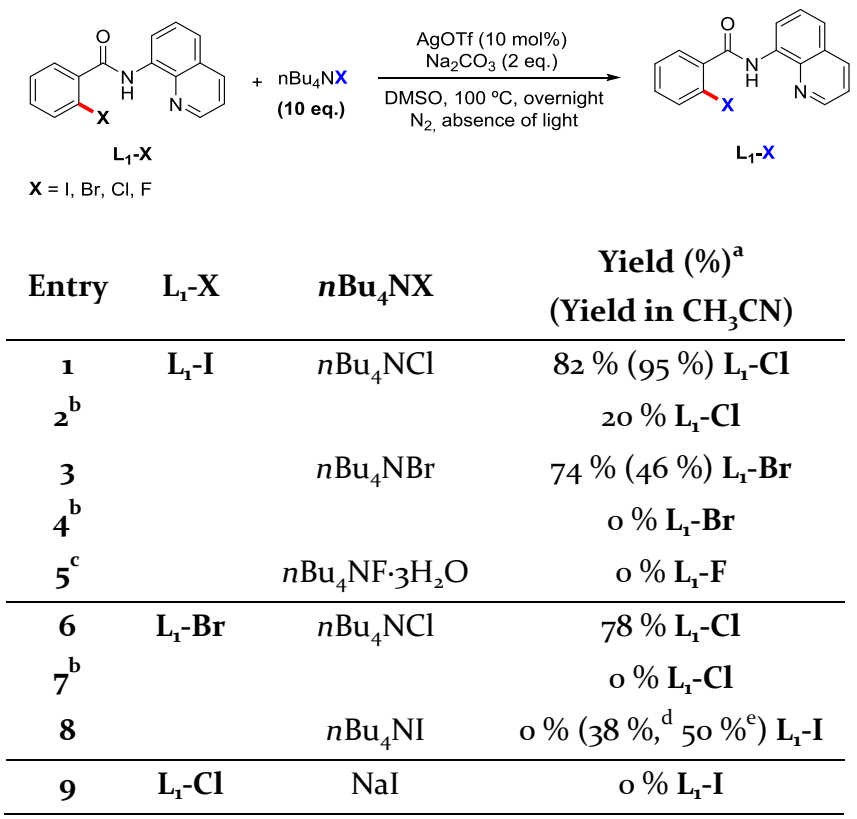

${ }^{\mathrm{a}}$ Yield calculated from ${ }^{1} \mathrm{H}-\mathrm{NMR}$ of crude using trimethoxybenzene as internal standard. ${ }^{b}$ The reaction was carried out without AgOTf. ${ }^{\mathrm{c}}$ Using $10 \mathrm{~mol} \%$ of AgF. Side reaction was observed (34\% yield of $\mathbf{L}_{\mathbf{1}}$-DMSO). ${ }^{\mathrm{d}}$ Using $20 \mathrm{~mol} \%$ of AgOTf. ${ }^{\mathrm{e}}$ Using $20 \mathrm{~mol} \%$ of AgOTf and $20 \mathrm{~mol} \%$ of $\mathrm{PPh}_{3}$.

Table 2. Ag-catalyzed $\mathrm{C}-\mathrm{N}$ bond forming reactions

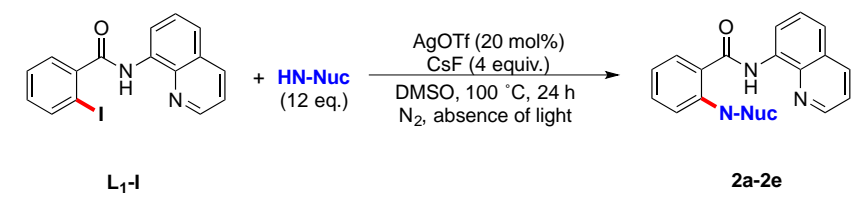

\begin{tabular}{|c|c|c|c|}
\hline Entry & Nuc. & Yield $(\%)^{a}$ & $\begin{array}{c}\text { Conv. } \\
(\%)\end{array}$ \\
\hline $\mathbf{1}^{\mathbf{b}}$ & & $53 \%(51 \%) \mathbf{2 a}$ & $>99 \%$ \\
\hline $2^{c}$ & & o \% $\mathbf{2 a}$ & $5 \%$ \\
\hline $3^{b}$ & & $37 \%(31 \%) \mathbf{2 b}$ & $>99 \%$ \\
\hline 4 & & $59 \%(54 \%) \mathbf{2 c}$ & $71 \%$ \\
\hline 5 & & $79 \%(61 \%) \mathbf{2 d}$ & $>99 \%$ \\
\hline $6^{d}$ & & $85 \%(59 \%) \mathbf{2 e}$ & $>99 \%$ \\
\hline $7^{b}$ & & $33 \%(30 \%) 2 f$ & $86 \%$ \\
\hline
\end{tabular}

${ }^{\mathrm{a}}$ Yield calculated from ${ }^{1} \mathrm{H}-\mathrm{NMR}$ of crude using trimethoxybenzene as internal standard (isolated yield in parenthesis). ${ }^{b}$ Side reactions were observed: $18 \%$ of $\mathbf{L}_{\mathbf{1}}-\mathbf{H}$ and $19 \%$ of $\mathbf{L}_{\mathbf{1}}-\mathbf{L}_{\mathbf{1}}$ homocoupling (entry 1 ), $10 \%$ of $\mathbf{L}_{\mathbf{1}}-\mathbf{H}$ and $18 \%$ of $\mathbf{L}_{\mathbf{1}}-\mathbf{L}_{\mathbf{1}}$ homocoupling (entry 3), traces of $\mathbf{L}_{\mathbf{1}}-\mathbf{H}$ and $10 \%$ of $\mathbf{L}_{\mathbf{1}}-\mathbf{L}_{\mathbf{1}}$ homocoupling (entry 7 ). ${ }^{\mathrm{c}}$ The reaction was carried out without AgOTf. ${ }^{d}$ Using $\mathbf{L}_{\mathbf{2}}-\mathbf{I}$ as a substrate.
We then explored the silver-catalyzed aryl-O crosscouplings with phenols bearing different parasubstituents ( $\mathrm{R}=\mathrm{H}, \mathrm{Cl}, \mathrm{OMe}, \mathrm{NO}_{2}$ ) (Table 3 ). In this case, reactions were optimized in DMSO and $t \mathrm{BuOK}$ as a base. Good yields were obtained for phenol (73\%, 3a) and $p-C l-$ phenol $(74 \%, 3 \mathbf{b})$, whereas low yield was obtained when electron donating $p$-MeO-phenol was used $(38 \%, 3 c)$. Surprisingly, the reaction was completely ineffective when $p-\mathrm{NO}_{2}$-phenol was used as nucleophile. These results suggest that deprotonation is not a key step in the C$\mathrm{O}$ coupling reaction and that a correct electronic balance is needed to achieve the desired coupling products. We also attempted the cross-coupling catalysis with $\mathrm{CH}_{3} \mathrm{OH}$ as nucleophile, but only stoichiometric amounts of the desired ze coupling product were obtained when 10 and $20 \mathrm{~mol} \%$ of AgOTf were used $\left(\mathrm{CH}_{3} \mathrm{OH}\right.$ as solvent and $t \mathrm{BuOK}$ as a base).

Table 3. Ag-catalyzed $\mathrm{C}-\mathrm{O}$ bond forming reactions

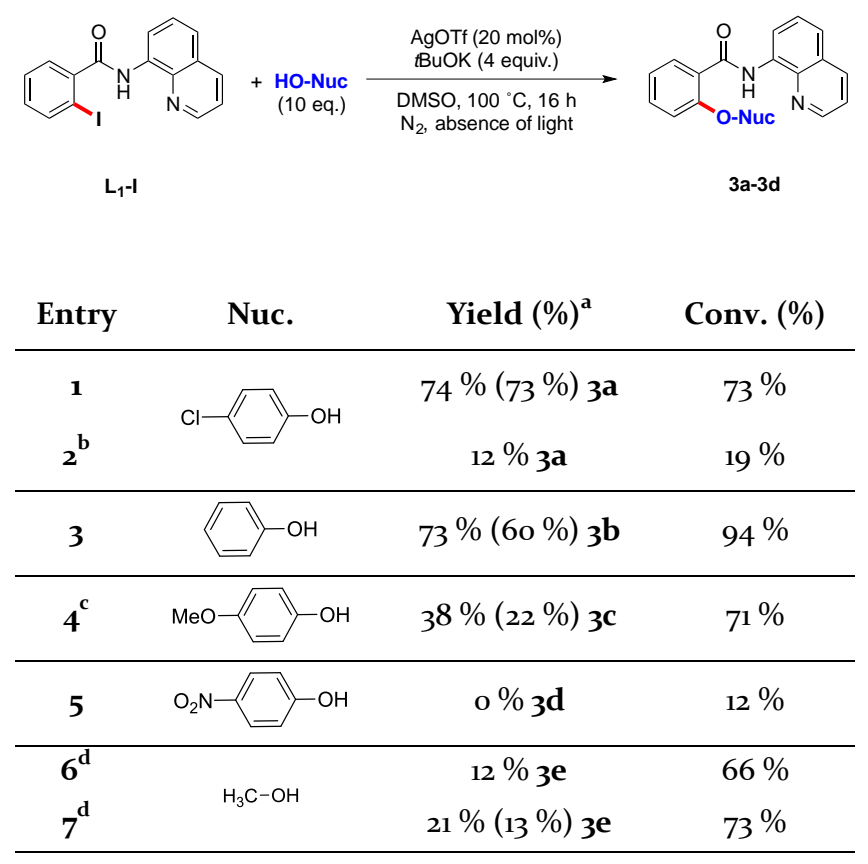

${ }^{\text {a }}$ Yield calculated from ${ }^{1} \mathrm{H}-\mathrm{NMR}$ of crude using trimethoxybenzene as internal standard (isolated yield in parenthesis). ${ }^{b}$ The reaction was carried out without AgOTf. ${ }^{c} 32 \%$ of $\mathbf{L}_{\mathbf{1}}-\mathbf{H}$. ${ }^{\mathrm{d}}$ Using $2.5 \mathrm{~mL}$ of $\mathrm{MeOH}$ instead of DMSO, $10 \mathrm{~mol} \%$ of AgOTf was used (entry 6).

Finally, C-C cross-couplings were explored using activated methylene-type substrates (Hurtley-type couplings), nitromethane and $p$-MeO-phenylboronic acid (Table 4). Under the optimized conditions (DMSO as solvent, $t \mathrm{BuOK}$ as a base and $20 \mathrm{~mol} \%$ AgOTf), malononitrile afforded a $74 \%$ yield of the coupling product 4aa, which consists of an initial C-C coupling and a subsequent cyclization by nucleophilic attack of the amide to one of the -CN groups (entry 1). The blank experiment did not afford 4aa (entry 2). The same product 4 aa was obtained in $90 \%$ yield in $\mathrm{CH}_{3} \mathrm{CN}$, but some degree of decomposition of acetonitrile to form trimeric triazine-coupled product was 
observed, ${ }^{20}$ thus the solvent of choice was DMSO for the other C-nucleophiles. When ethyl 2-cyanoacetate was used, $48 \%$ yield of $\mathbf{4} \mathbf{b}$ was obtained (entry 3 ), which is the C-C coupling product without further intramolecular reorganization. In this case, only $9 \%$ yield of $\mathbf{4 b a}$, the intramolecular cyclization product analogous to 4aa, was obtained. On the other hand, dimethyl malonate afforded $62 \%$ yield of 4 ca which corresponds to the cyclic product formed by a nucleophilic attack of the amide to one of the carbonyl groups (with loss of $\mathrm{MeOH}$ ). In the case of acetylacetone and ethyl 2-nitroacetate, the catalysis was completely ineffective. Surprisingly, nitromethane worked well as nucleophile yielding a 59\% yield of $4 \mathrm{fa}$, which bears an isoindolin-1-one formed after the loss of the nitro group. Also, $16 \%$ of $\mathbf{L}_{\mathbf{1}}$-DMSO is obtained (coupling of a deprotonated DMSO solvent molecule).

Table 4. Ag-catalyzed C-C bond forming reactions

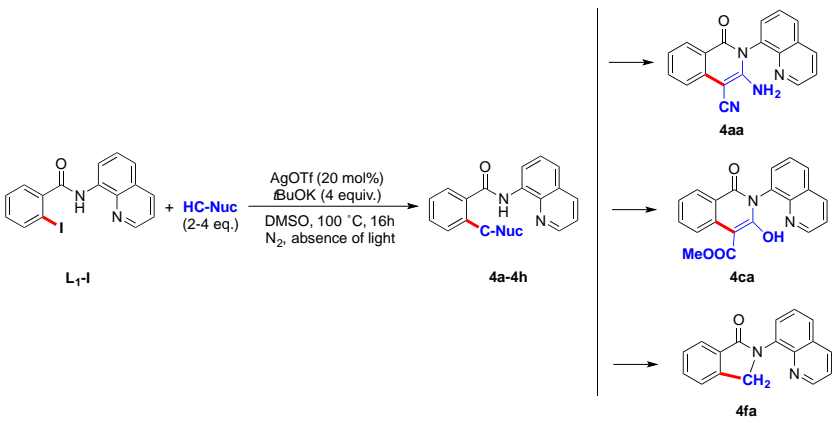

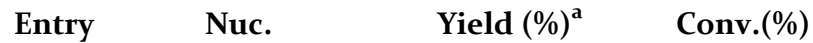

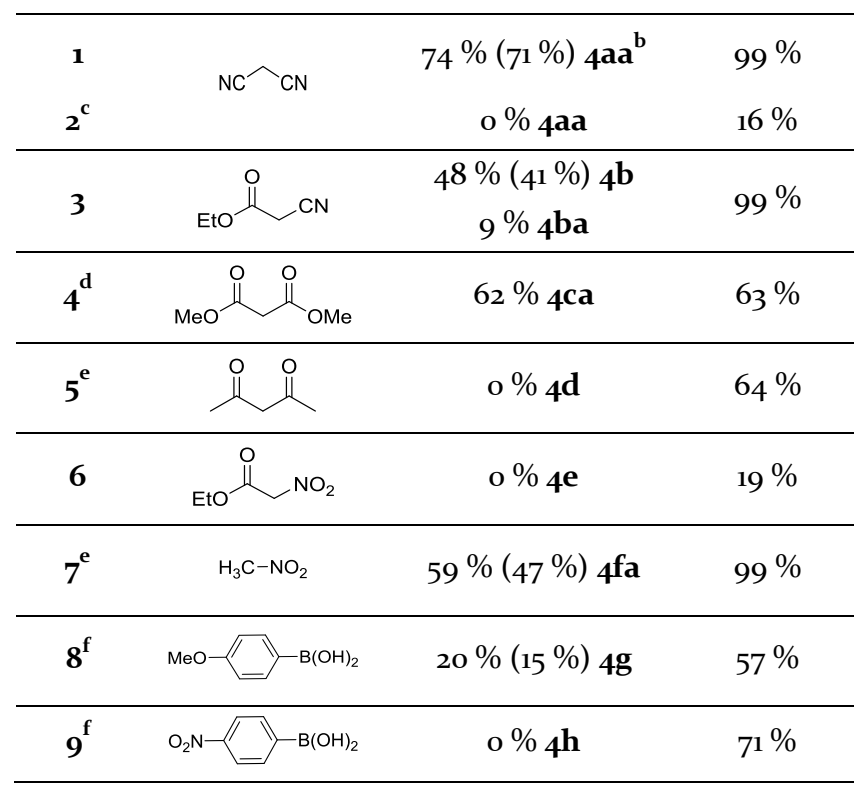

${ }^{\mathrm{a}}$ Yield calculated from ${ }^{1} \mathrm{H}-\mathrm{NMR}$ of crude using trimethoxybenzene as internal standard (isolated yield in parenthesis). ${ }^{b} 90 \%$ of 4 aa was obtained using $\mathrm{CH}_{3} \mathrm{CN}$ as solvent. ${ }^{\mathrm{c}}$ The reaction was carried out without AgOTf. ${ }^{\mathrm{d}}$ The reaction was carried out using DMSO- $\mathrm{d}_{6} \cdot{ }^{\mathrm{e}}$ Side reactions were observed 15 $\%$ of $\mathbf{L}_{\mathbf{1}}-\mathbf{H}$ (entry 5 ) and $16 \%$ of $\mathbf{L}_{\mathbf{1}}$-DMSO (entry 7 ). ${ }^{\mathrm{f}}$ The reaction was carried out using 10 equiv. of arylboronic acid at $120 \stackrel{\circ}{ } \mathrm{C}$.
Finally, arylboronic acids were also tested due to the effective reductive elimination observed using the triazamacrocyclic aryl-Ag(III) species. $^{9}$ In the noncyclized substrate, only $20 \%$ yield of the biaryl C-C coupling product $\mathbf{4 g}$ was obtained, suggesting that transmetallation and reductive elimination occurred but the system could not enter into catalytic turnover. When p- $\mathrm{NO}_{2}$-phenylboronic acid was used no coupling product was obtained, presumably because of the destabilizing effect of the electronwithdrawing group over the $\mathrm{Ag}$ (III) center.

Discarding contamination of other metals. Given the unusual two-electron redox $\mathrm{Ag}(\mathrm{I}) / \mathrm{Ag}(\mathrm{III})$ reactivity, we analyzed two AgOTf commercial samples by ICP-MS searching the content of traces of other possibly active metals in cross-coupling reactions, specifically $\mathrm{Pd}$ and $\mathrm{Cu}$. No traces of $\mathrm{Pd}$ were found, and $0.01 \%$ content of $\mathrm{Cu}$ was determined in two batches of AgOTf. We then reproduced three of the above coupling reactions using $\left[\mathrm{Cu}\left(\mathrm{CH}_{3} \mathrm{CN}\right)_{4}\right] \mathrm{OTf}$ as catalyst at $0.002 \mathrm{~mol} \%$ (the content of $\mathrm{Cu}$ traces when using a $20 \mathrm{~mol} \%$ AgOTf). No significant product yields were found (Table 5). In addition, the coupling reactions were also tested in the presence of $\mathrm{Cu}(\mathrm{OTf})_{2}$, which might have a role if $\mathrm{Ag}(\mathrm{o})$ was formed in situ and was reoxidized to $\mathrm{Ag}(\mathrm{I})$. Again, no significant yields were obtained. Therefore, yields obtained using $0.002 \mathrm{~mol} \%\left[\mathrm{Cu}\left(\mathrm{CH}_{3} \mathrm{CN}\right)_{4}\right] \mathrm{OTf}$ or $\mathrm{Cu}(\mathrm{OTf})_{2}$ in the coupling catalysis tested clearly discard any significant role of $\mathrm{Cu}$, and underlines silver as the main catalyst (Table 5).

Table 5. Comparison of coupling reactions catalyzed by $\mathrm{Ag}$ or $\mathrm{Cu}$ impurities.

Yield (Conv.)

\begin{tabular}{|c|c|c|c|c|}
\hline Entry & Nuc. & $\begin{array}{l}\operatorname{Ag}(\text { OTf }) \\
(20 \text { mol\%) }\end{array}$ & $\begin{array}{l}\mathrm{Cu}(\mathrm{OTf})^{\mathrm{a}} \\
(\mathrm{o.002} \%)\end{array}$ & $\begin{array}{l}\mathrm{Cu}(\mathrm{OTf})_{2} \\
(\mathrm{o.002} \%)\end{array}$ \\
\hline $\mathbf{1}$ & & $\begin{array}{c}53 \% \text { of } 2 a \\
(99 \%)\end{array}$ & $\begin{array}{c}6 \% \text { of } \mathbf{2 a} \\
(6 \%)\end{array}$ & $\begin{array}{c}9 \% \text { of } 2 a \\
(24 \%)\end{array}$ \\
\hline 2 & & $\begin{array}{c}79 \% \text { of } \mathbf{2 d} \\
(99 \%)\end{array}$ & $\begin{array}{c}24 \% \text { of } \\
\text { 2d }(24 \%)\end{array}$ & - \\
\hline 3 & & $\begin{array}{c}74 \% \text { of } 4 \text { aa } \\
(99 \%)\end{array}$ & $\begin{array}{c}\text { o } \% \text { of } \\
\mathbf{4 a / 4 a a} \\
(36 \%)\end{array}$ & $\begin{array}{c}12 \% \text { of } 4 \text { aa } \\
(37 \%)\end{array}$ \\
\hline
\end{tabular}

${ }^{\mathrm{a}}$ Using $\left[\mathrm{Cu}\left(\mathrm{CH}_{3} \mathrm{CN}\right)_{4}\right]$ OTf.

To further discard the activity of other impurities, small contents of HOTf, a typical impurity in triflate salts, were added in a AgOTf-catalyzed halide exchange reactions. The reactions in Table 1, entries 3 and 6 were repeated using $10 \mathrm{~mol} \%$ AgOTf and HOTf (5\% with respect to AgOTf), and smaller yields were obtained in both cases ( $55 \%$ of $\mathbf{L}_{\mathbf{1}}-\mathbf{B r}$ and $68 \%$ of $\mathbf{L}_{\mathbf{1}}-\mathbf{C l}$, respectively), discarding any beneficial role of triflic acid impurities.

Computational insight into the mechanism of the Ag-catalyzed cross-couplings. In order to gain insight 
into the role of silver in the catalysis mechanism, DFT studies (see SI for details) were performed focusing on the I-to- $\mathrm{Cl}$ halide exchange reaction (Figure 2). We determined that the aryl-I oxidative addition step $\left(\mathrm{TS}_{1}\right)$ lies at $24.7 \mathrm{kcal} \cdot \mathrm{mol}^{-1}$, rendering the key $\left[\mathbf{L}_{1}-\mathbf{A g}(\mathrm{III})-\mathbf{C l}\right](\mathrm{I})$ species. The latter shows a square-pyramidal geometry with I at the apical position $\left(\mathrm{d}_{\mathrm{Ag}-\mathrm{I}}=3.7 \AA\right)$, conforming to a $\mathrm{d}^{8}$ electronic configuration for $\mathrm{Ag}(\mathrm{III})$ in an analogous manner as well-defined aryl- $\mathrm{Ag}(\mathrm{III})$ species isolated in triazamacrocyclic scaffolds. ${ }^{9}\left[\mathbf{L}_{1}-\mathbf{A g}(\mathrm{III})-\mathbf{C l}\right](\mathrm{I})$ undergoes subsequent aryl- $\mathrm{Cl}$ reductive elimination $\left(\mathrm{TS}_{2}=28.1\right.$ $\left.\mathrm{kcal} \cdot \mathrm{mol}^{-1}\right)$ to obtain the final $\left(\mathbf{L}_{\mathbf{1}}-\mathbf{C l}\right)$ AgI compound. The barrier of $28.1 \mathrm{kcal} \cdot \mathrm{mol}^{-1}$ agrees with the high temperature $\left(100^{\circ} \mathrm{C}\right)$ needed for the reaction to take place. It is noteworthy that the reverse reaction, formally the aryl- $\mathrm{Cl}$ oxidative addition, has a larger barrier (up to 32.5 $\left.\mathrm{kcal} \cdot \mathrm{mol}^{-1}\right)$ and conforms to the unobserved halide exchange when $\mathbf{L}_{\mathbf{1}}-\mathbf{C l}$ is used as substrate.

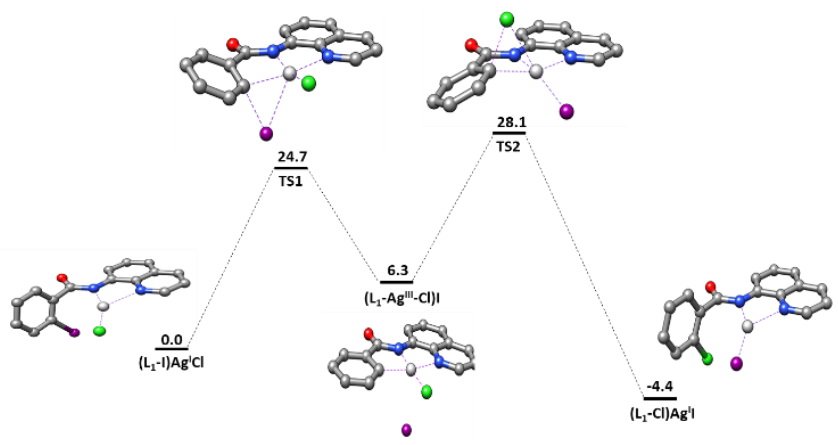

Figure 2. Gibbs energy profile of the oxidative addition and reductive elimination steps in the $\mathbf{L}_{\mathbf{1}}-\mathbf{I}-$ to $_{-}-\mathbf{L}_{\mathbf{1}}-\mathbf{C l}$ halide exchange reaction.

Experimental IRPD-MS analysis of operando catalysis. Aiming for direct experimental proof of aryl-Ag(III) active species, we applied high resolution mass spectrometry (HRMS) and helium tagging infrared photodissociation (IRPD) spectroscopy to our system. ${ }^{16-19}$ Initial HRMS analysis at short reaction times of the reactions using $\mathbf{L}_{\mathbf{1}}-\mathbf{I}$ and stoichiometric amounts of silver salt in $\mathrm{CH}_{3} \mathrm{CN}$ (suitable solvent for the HRMS analysis) showed significant amounts of $\mathrm{C}-\mathrm{N}$ homocoupling products. This result was a good indication of aryl-I activation but complicated the analysis. To simplify the reaction and the ulterior analysis, we designed the oMe- $\mathrm{L}_{1}-\mathrm{I}\left(\mathbf{L}_{2}-\mathbf{I}\right)$ substrate to minimize the formation of homocoupling products by steric hindrance. For instance, using $\mathbf{L}_{2}-\mathbf{I}$ as a substrate and $p \mathrm{NO}_{2}$-aniline as a nucleophile for the silver-catalyzed $\mathrm{C}-\mathrm{N}$ coupling affords $85 \%$ of 2 e. Focusing in the MS study, no nucleophile was added to the reaction in order to analyze only the putative $\left[\mathbf{L}_{\mathbf{2}}-\mathbf{A g}(\mathbf{I I I})\right]^{+}$species formed by aryl-I oxidative addition at $\operatorname{Ag}(\mathrm{I})$. The main peak observed at $\mathrm{m} / \mathrm{z}$ 494.9088 presumably corresponded to $\left[\left(\mathbf{L}_{2}-\mathbf{I}\right) \mathbf{A g}\right]^{+}$(Figure $\mathrm{Si})$. Noteworthy, small peak at $\mathrm{m} / \mathrm{z} 366.9987$ was detected, tentatively assigned to $\left[\mathbf{L}_{2}-\mathbf{A g}(\mathbf{I I I})\right]^{+}$.

In order to identify the structure of the detected silver complexes, we have recorded their IRPD spectra. It turned out that the theoretically predicted IR spectrum of $\left[\left(\mathbf{L}_{2}-\mathbf{I}\right) \mathbf{A g}\right]^{+}$nicely reproduced the IRPD spectrum of the ions with $\mathrm{m} / \mathrm{z} 495$ (Figure 3) ${ }^{21-26}$ It clearly confirmed that the detected $\mathrm{m} / \mathrm{z} 495$ ions peak correspond to the $\mathrm{Ag}(\mathrm{I})$ complexation to $\mathbf{L}_{2}-\mathbf{I}$. The putative silver(III) intermediate $(\mathrm{m} / \mathrm{z}$ 367) was detected as a complex with acetonitrile at softer ionization condition $(\mathrm{m} / \mathrm{z} 408)$. We assumed that acetonitrile fills in the fourth coordination site of the silver(III) complex and therefore stabilizes this intermediate. However, the experimental IRPD spectrum of the ions with $\mathrm{m} / \mathrm{z} 408$ and the theoretical spectrum of the proposed $\left[\mathbf{L}_{2}-\mathbf{A g}(\mathbf{I I I})-\left(\mathbf{C H}_{3} \mathbf{C N}\right)\right]^{+}$intermediate did not agree. In particular, the theoretical spectrum of this $\mathrm{Ag}$ (III) complex did not contain any bands that could be attributed to the experimental peaks at 1110 and $2770 \mathrm{~cm}^{-1}$. The search for alternative structures resulted in finding a series of more stable complexes with the same mass (see Figure $\mathrm{S}_{4}$ ). The theoretical IR spectrum for the complex $\left[{ }_{5} \mathbf{d}-\mathbf{A g}(\mathrm{I})-\mathrm{CH}_{3} \mathrm{CN}\right]^{+}$resulting from an intramolecular cyclization conformed to the experimental spectrum (Figure 4).

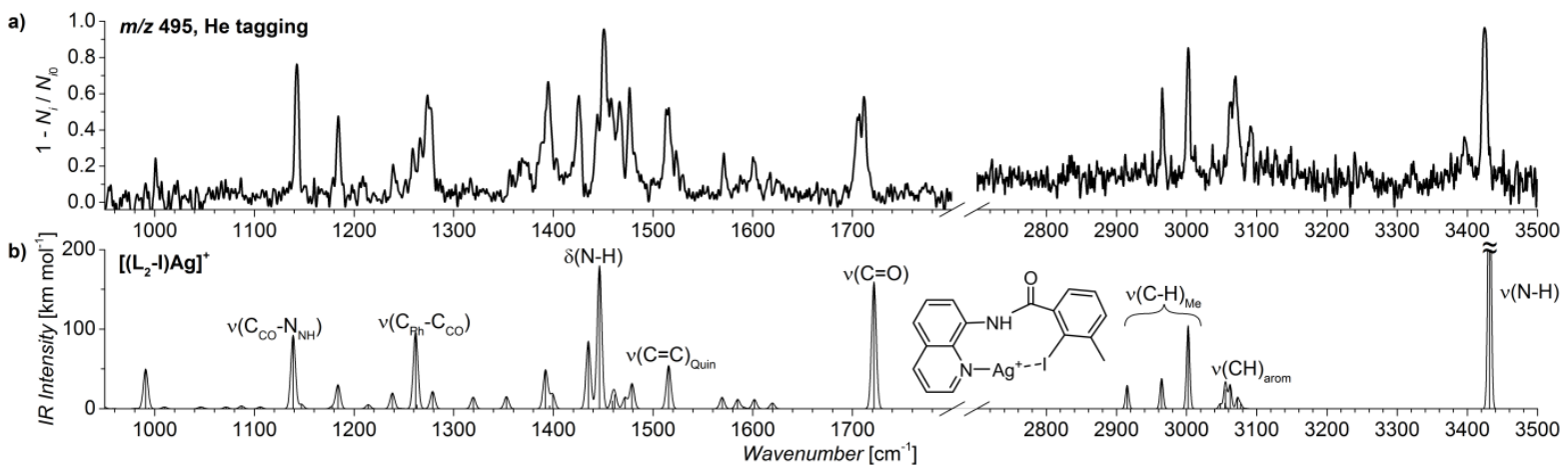

Figure 3. a) Helium tagging IRPD spectra of ions with $\mathrm{m} / \mathrm{z} 495$. b) Theoretical IR spectrum $\left(\mathrm{B}_{3} \mathrm{LYP}^{21-24}-\mathrm{D}_{3} \mathrm{~B}^{25-26} / 6\right.$ $311+\mathrm{g}(2 \mathrm{~d}, \mathrm{p}): \mathrm{SDD}-(\mathrm{Ag}, \mathrm{I})$ ) of $\left[\left(\mathbf{L}_{2}-\mathbf{I}\right)-\mathbf{A g}(\mathrm{I})\right]^{+}$. The scaling factor was 0.98 (below $2000 \mathrm{~cm}^{-1}$ ) and $0.96\left(\right.$ above $\left.2000 \mathrm{~cm}^{-1}\right)$. Predicted IR intensities above $2700 \mathrm{~cm}^{-1}$ were multiplied by 10 . 

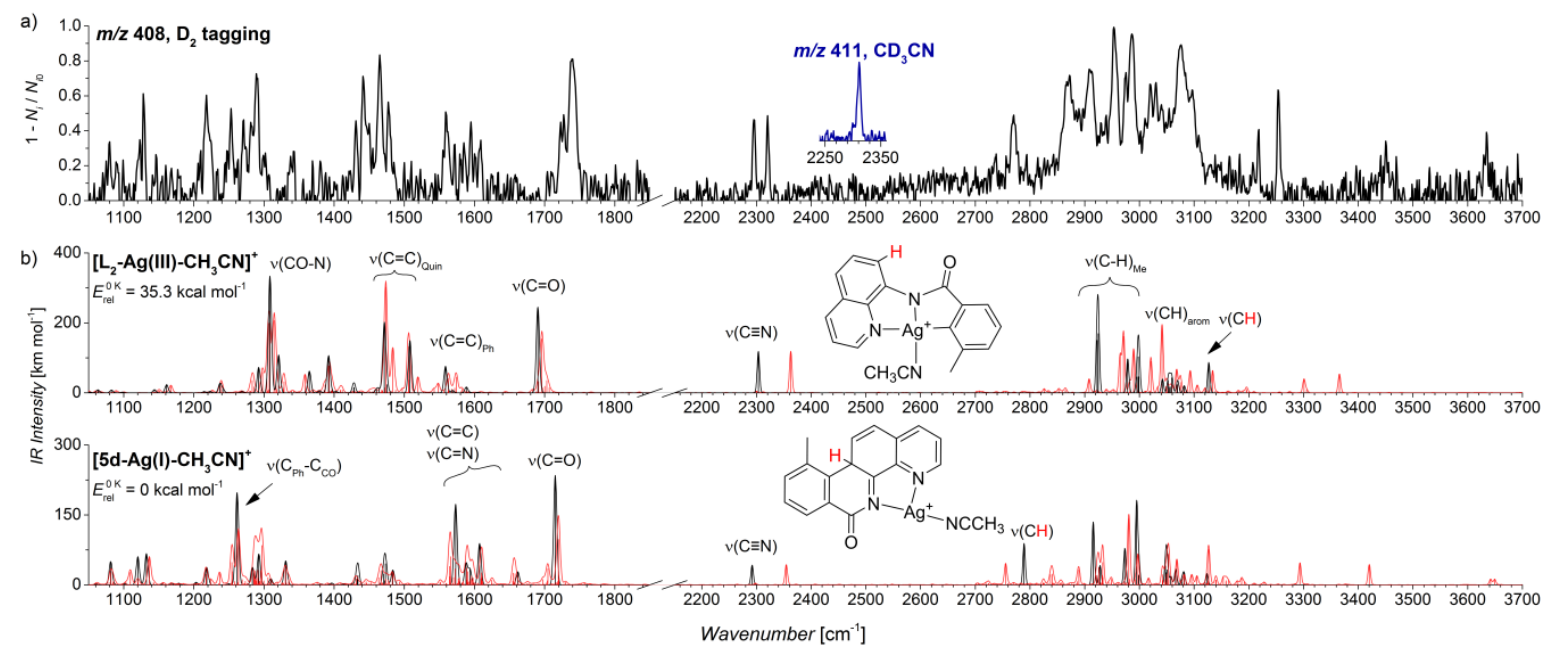

Figure 4. a) $\mathrm{D}_{2}$ tagging IRPD spectra of ions with $m / z$ 4o8. b) Theoretical IR spectra (B3LYP-D3 BJ/6-311+g(2d,p):SDD-Ag) of $\left[\mathbf{L}_{2}-\mathbf{A g}(\mathrm{III})-\mathbf{C H}_{3} \mathbf{C N}\right]^{+}$and $\left[{ }_{5} \mathbf{d}-\mathbf{A g}(\mathrm{I})-\mathbf{C H}_{3} \mathbf{C N}\right]^{+}$. The harmonic IR spectra are in black; the scaling factor was o.98 (below $\left.2000 \mathrm{~cm}^{-1}\right)$ and $0.96\left(\right.$ above $\left.2000 \mathrm{~cm}^{-1}\right)$. The anharmonic IR spectra $\left(B_{3} L Y P-D_{3} B J / 6-311+g(2 \mathrm{~d}, \mathrm{p}): S D D-A g\right)$ are in red and were not scaled. Predicted IR intensities above $2700 \mathrm{~cm}^{-1}$ were multiplied by 10 .

The formation of $\left[\mathbf{5} \mathbf{d}-\mathbf{A g}(\mathbf{I})-\mathbf{C H}_{3} \mathbf{C N}\right]^{+}$was rationalized as depicted in Scheme 2. The first species formed is the coordination of $\mathrm{Ag}(\mathrm{I})$ to the substrate $(\mathrm{m} / \mathrm{z}$ 495), which undergoes oxidative addition, formal loss of $\mathrm{HI}$ and coordination of one $\mathrm{CH}_{3} \mathrm{CN}$ molecule to transiently form the sought $\left[\mathbf{L}_{2}-\mathbf{A g}(\mathrm{III})-\left(\mathbf{C H}_{3} \mathbf{C N}\right)\right]^{+}$. Since IRPD analysis discarded that $\mathrm{m} / \mathrm{z} 408$ corresponded to the latter species, $\left[{ }_{5} \mathbf{d}-\mathbf{A g}(\mathrm{I})-\mathrm{CH}_{3} \mathbf{C N}\right]^{+}$was formed in the gas phase as an intramolecular cyclization of the transient aryl- $\mathrm{Ag}(\mathrm{III})$ via formation of a $\mathrm{Ag}(\mathrm{I})$ complex bearing a cationic benzenylium moiety (a theoretical energy of $17 \mathrm{kcal} \cdot \mathrm{mol}^{-1}$ was calculated for this intermediate), which rapidly collapses to produce $\left[{ }_{5} \mathbf{d}-\mathbf{A g}(\mathrm{I})-\mathrm{CH}_{3} \mathbf{C N}\right]^{+}$. In solution, further proton-

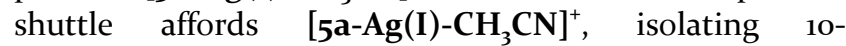
methylbenzo[c][1,10]phenanthrolin-6(5) -one $(5 \mathbf{a})$ as the final organic product.

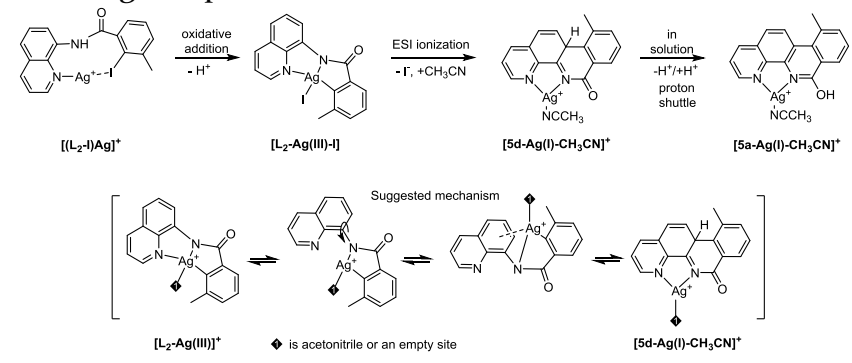

Scheme 2. Suggested mechanism of the formation of $\left[5^{\mathrm{a}-}\left(\mathrm{Ag}(\mathrm{I})-\mathrm{CH}_{3} \mathrm{CN}\right]\right.$, the experimentally observed intermediate.

To clarify whether $\left[\mathbf{5} \mathbf{d}-\mathbf{A g}(\mathbf{I})-\mathbf{C H}_{3} \mathbf{C N}\right]^{+}$was only formed in the gas phase or it was also formed in the reaction mixture, we repeated the reaction at $\sim 0.1 \mathrm{~g}$ scale in order to isolate the products of the reaction of $\mathbf{L}_{2}-\mathbf{I}$ and $\mathrm{AgClO}_{4}$ in the presence of $\mathrm{Na}_{2} \mathrm{CO}_{3}$. Upon optimization $\left(100{ }^{\circ} \mathrm{C}, 24 \mathrm{~h}\right)$, analysis by HRMS of the reaction crude indicated that a compound at $\mathrm{m} / \mathrm{z} 261$ appeared mixed with starting $\mathbf{L}_{2}-\mathbf{I}$ and byproducts. After chromatographic purification of the 261 peak, NMR and HRMS characterization confirmed the formation of the intramolecular cyclization organic product (5a) (Scheme 3), which results from a tautomerization of tautomer of $\mathbf{5} \mathbf{d}$.

Global mechanism. The mechanistic proposal depicted in Scheme 3 is derived from all the experimental and theoretical results disclosed in this work. The initial step of the reaction conforms to an aryl-halide oxidative addition that converges into the key aryl-Ag(III) species. This species is at a crossroads depending on whether the nucleophile is present in the reaction mixture. If present, nucleophile coordination and reductive elimination affords the desired coupling product following a 2-electron $\mathrm{Ag}(\mathrm{I}) / \mathrm{Ag}(\mathrm{III})$ catalysis. If absent, the highly reactive aryl$\mathrm{Ag}$ (III) species undergoes an intramolecular cyclization reaction to form the experimentally characterized 10methylbenzo[c][1,10]phenanthrolin-6 $\left.{ }_{5} \mathrm{H}\right)$-one $\quad(5 a)$ species. 


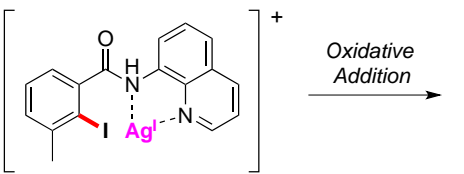

$\left[\left(\mathrm{L}^{-\mathrm{I}}\right)-\mathrm{Ag}(\mathrm{I})\right]^{+}$

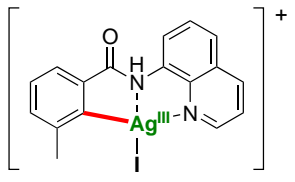

[(L $\left.{ }^{-}-\mathrm{Ag}(\mathrm{III})-\mathrm{I}\right]$

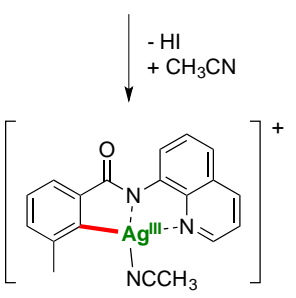

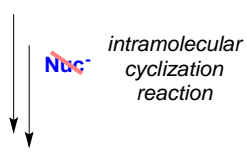

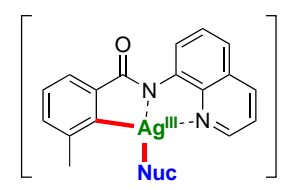

$\downarrow+\mathrm{H}^{+}$

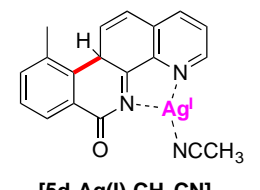

[5d-Ag(I)- $\left.\mathrm{CH}_{3} \mathrm{CN}\right]$
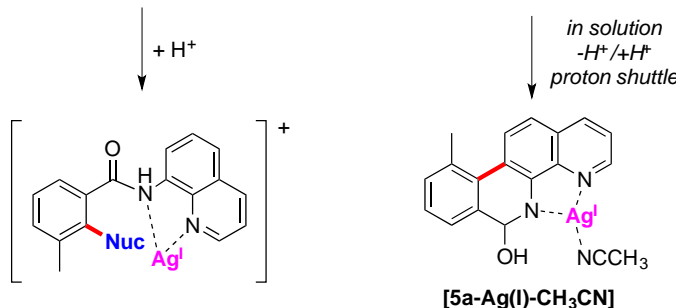

[5a-Ag(I)- $\mathrm{CH}_{3} \mathrm{CN}$ ]

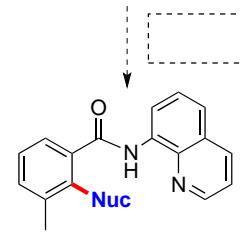

cross coupling product

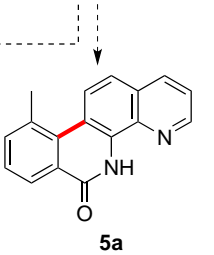

Scheme 3. Global mechanistic proposal in solution.

\section{CONCLUSIONS}

The ability of silver to undergo non-canonical 2-electron redox $\mathrm{Ag}(\mathrm{I}) / \mathrm{Ag}(\mathrm{III})$ cross-coupling catalysis for Cheteroatom and C-C bond formation has been successfully proven for a non-cyclic substrate bearing an aminoquinoline bidentate DG $\left(\mathbf{L}_{1}-\mathbf{I}\right)$. Contrary to the rigid triazamacrocyclic model firstly used to isolate a welldefined aryl-Ag(III) complex, the non-cyclic $\mathbf{L}_{\mathbf{1}} \mathbf{- I}$ supports the same kind of intermediate species but much more reactive. Despite our attempts to directly detect organometallic aryl-Ag(III) species, those remained elusive although their existence is clearly inferred experimentally and theoretically in the four kinds of cross-coupling catalysis studied (halide exchange, $\mathrm{C}-\mathrm{N}, \mathrm{C}-\mathrm{O}$ and $\mathrm{C}-\mathrm{C}$ couplings), and also in the IRPD-MS studies without nucleophile. The sharply enhanced reactivity of this species in non-cyclic substrates compared to macrocyclic substrates

was also observed when studying $\mathrm{Cu}(\mathrm{III})$ intermediate species. ${ }^{18}$ We envision that this work might trigger more research efforts on Ag-catalyzed cross-couplings, to further evaluate its use as an actual synthetic tool in organic synthesis, complementary to the well-known $\mathrm{Pd}(\mathrm{o}) / \mathrm{Pd}(\mathrm{II})$ and $\mathrm{Cu}(\mathrm{I}) / \mathrm{Cu}(\mathrm{III})$.

\section{AUTHOR INFORMATION}

\section{Corresponding Author}

* jana.roithova@ru.nl

* xavi.ribas@udg.edu

\section{ASSOCIATED CONTENT}

Supporting Information. Detailed spectroscopic characterization of all compounds is included. Also, computational DFT data and technical details of the IRPD experiments are included. This material is available free of charge via the Internet at http://pubs.acs.org.

\section{ACKNOWLEDGMENT}

This work was financially supported by grants from the European Research Council (Starting Grant Project ERC-2011StG-277801 to XR and ERC-2015-CoG-682275 (IsoMS) to JR), the Spanish MICINN (CTQ2016-77989-P to XR), and the Catalan DIUE of the Generalitat de Catalunya (2017SGR264). X.R. thanks ICREA for an ICREA Acadèmia award. We thank COST Action CHAOS (CA15106) and STR from UdG for technical support.

\section{REFERENCES}

1. Hickman, A. J.; Sanford, M. S., High-valent organometallic copper and palladium in catalysis. Nature 2012, 484, 177-185.

2. Wolfe, J. P.; Wagaw, S.; Marcoux, J.-F.; Buchwald, S. L., Rational Development of Practical Catalysts for Aromatic Carbon-Nitrogen Bond Formation. Acc. Chem. Res. 1998, 31, 805-818.

3. Hartwig, J. F., Carbon-Heteroatom BondForming Reductive Elimination of Amines, Ethers and Sulfides. Acc. Chem. Res. 1998, 31, 852-860.

4. $\quad$ Casitas, A.; Ribas, X., The role of organometallic copper(III) complexes in homogeneous catalysis. Chem. Sci. 2013, 4, 2301-2318.

5. $\quad$ Evano, G.; Blanchard, N., Copper-Mediated CrossCoupling Reactions. John Wiley \& Sons, Hoboken: 2014.

6. Weibel, J.-M.; Blanc, A. 1.; Pale, P., Ag-Mediated Reactions: Coupling and Heterocyclization Reactions. Chem. Rev. 2008, 108, 3149-3173.

7. Font, M.; Ribas, X., Pincerlike Cyclic Systems for Unraveling Fundamental Coinage Metal Redox Processes. In The Privileged Pincer-Metal Platform: Coordination Chemistry \& Applications, van Koten, G.; Gossage, R. A., Eds. Springer International Publishing: 2016; Vol. 54, pp 269-306. 
8. Mijs, W. J.; Jong, C. R. H. I. d., Organic Synthesis by Oxidation with Metal Complexes. Plenum Press: New York, 1986.

9. $\quad$ Font, M.; Acuña-Parés, F.; Parella, T.; Serra, J.; Luis, J. M.; Lloret-Fillol, J.; Costas, M.; Ribas, X., Direct observation of two-electron $\mathrm{Ag}(\mathrm{I}) / \mathrm{Ag}(\mathrm{III})$ redox cycles in coupling catalysis. Nat. Commun. 2014, 5:4373.

10. Li, P.; Wang, L., A Novel Silver Iodide Catalyzed Sonogashira Coupling Reaction. Synlett 2006, 2006, 22612265.

11. Das, R.; Mandal, M.; Chakraborty, D., SilverNitrate-Catalyzed N-Arylation of Amines and OArylations of Phenols and Alcohols. Asian J. Org. Chem. 2013, 2, 579-585.

12. Rovira, M.; Soler, M.; Güell, I.; Wang, M.-Z.; Gómez, L.; Ribas, X., Orthogonal Discrimination among Functional Groups in Ullmann-Type $\mathrm{C}-\mathrm{O}$ and $\mathrm{C}-\mathrm{N}$ Couplings. J. Org. Chem. 2o16, 81, 7315-7325.

13. Ribas, X.; Güell, I., $\mathrm{Cu}(\mathrm{I}) / \mathrm{Cu}(\mathrm{III})$ catalytic cycle involved in Ullmann-type cross-coupling reactions. Pure Appl. Chem. 2014, 86, 263-467.

14. Rovira, M.; Font, M.; Ribas, X., Model Csp2-Csp3 Hurtley Coupling Catalysis that Operates through a WellDefined CuI/CuIII Mechanism. ChemCatChem 2013, 5, 687-691.

15. Jašík, J.; Gerlich, D.; Roithová, J., Two-Color Infrared Predissociation Spectroscopy of C6H62+ Isomers Using Helium Tagging. J. Phys. Chem. A 2015, 119, 25322542.

16. Jašík, J.; Žabka, J.; Roithová, J.; Gerlich, D., Infrared spectroscopy of trapped molecular dications below 4 K. Int. J. Mass Spectrom. 2013, 354-355, 204-210.

17. Roithova, J., Characterization of reaction intermediates by ion spectroscopy. Chem. Soc. Rev. 2012, 41, 547-559.

18. Rovira, M.; Jasikova, L.; Andris, E.; Acuna-Pares, F.; Soler, M.; Guell, I.; Wang, M.-Z.; Gomez, L.; Luis, J. M.; Roithova, J.; Ribas, X., A CuI/CuIII prototypical organometallic mechanism for the deactivation of an active pincer-like CuI catalyst in Ullmann-type couplings. Chem. Commun. 2017, 53, 8786-8789.
19. Roithová, J.; Gray, A.; Andris, E.; Jašík, J.; Gerlich, D., Helium Tagging Infrared Photodissociation Spectroscopy of Reactive Ions. Acc. Chem. Res. 2016, 49, 223-230.

20. Zhaoxiang, D.; Wenfeng, Q.; Weijia, L.; Yadong, L., Cyclotrimerization of nitriles catalyzed by Li_3N. Chin. Sci. Bull. 2004, 49, 127-130.

21. Becke, A. D., Density-functional thermochemistry. III. The role of exact exchange. J. Chem. Phys. 1993, 98, 5648-5652.

22. Lee, C.; Yang, W.; Parr, R. G., Development of the Colle-Salvetti correlation-energy formula into a functional of the electron density. Phys. Rev. B 1988, 37, 785-789.

23. Miehlich, B.; Savin, A.; Stoll, H.; Preuss, H., Results obtained with the correlation energy density functionals of becke and Lee, Yang and Parr. Chem. Phys. Lett. 1989, 157, 200-206.

24. Stephens, P. J.; Devlin, F. J.; Chabalowski, C. F.; Frisch, M. J., Ab Initio Calculation of Vibrational Absorption and Circular Dichroism Spectra Using Density Functional Force Fields. J. Phys. Chem. 1994, 98, 1162311627.

25. Grimme, S.; Antony, J.; Ehrlich, S.; Krieg, H., A consistent and accurate $\mathrm{ab}$ initio parametrization of density functional dispersion correction (DFT-D) for the 94 elements H-Pu. J. Chem. Phys. 2010, 132, 154104.

26. Grimme, S.; Ehrlich, S.; Goerigk, L., Effect of the damping function in dispersion corrected density functional theory. J. Comput. Chem. 2o11, 32, 1456-1465. 
TOC

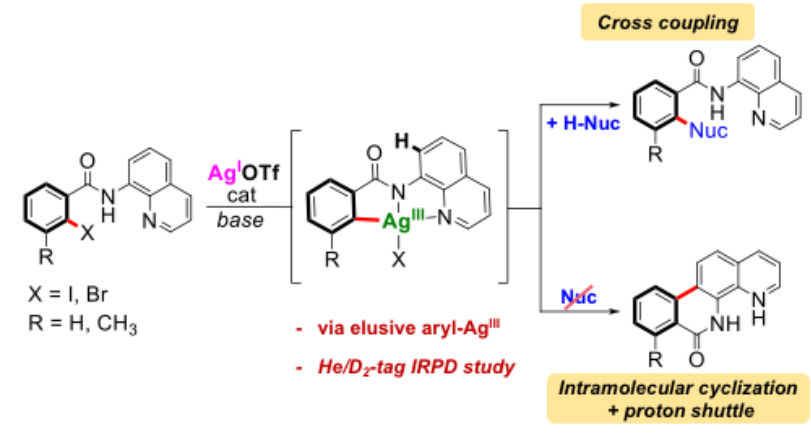

